\title{
Metodologia de Avaliação de Portais da Transparência Municipais
}

\section{Alternative Title: Evaluation Methodology of Municipal Transparency Websites}

\author{
Rogelio Pegoretti C. Amorim \\ Programa de Pós-Graduação em Informática \\ Universidade Federal do Espírito Santo \\ Av. Fernando Ferrari, 514, CT7- Vitória - ES \\ rogelio.amorim@gmail.com
}

\author{
Crediné Silva de Menezes \\ Programa de Pós-Graduação em Informática \\ Universidade Federal do Espírito Santo \\ Av. Fernando Ferrari, 514, CT7-Vitória - ES \\ credine@inf.ufes.br
}

\begin{abstract}
RESUMO
Este artigo aborda a necessidade do estudo da Transparência Governamental sob a ótica da Tecnologia da Informação. Para tanto, é apresentada a construção de uma Metodologia de Avaliação de Portais da Transparência Municipais, à luz das normas da série ISO/IEC 25000 e da legislação brasileira. O modelo proposto conta com 443 itens de avaliação, divididos em um indicador específico para medir o grau de Transparência Ativa do Poder Legislativo e outro para o Poder Executivo municipal. A metodologia construída se baseou em critérios objetivos para a atribuição dos pesos de cada indicador e teve foco em reduzir o grau de subjetividade do processo de execução da avaliação. $\mathrm{O}$ trabalho contou, ainda, com o desenvolvimento de um software de apoio operacional ao processo de avaliação, para agilizar o trabalho de campo. A metodologia foi aplicada com a realização da medição da transparência ativa dos municípios do Estado do Espírito Santo, e os resultados mostraram um baixo grau de atingimento dos critérios estabelecidos.
\end{abstract}

\section{Palavras-Chave}

Transparência; Governo Eletrônico; Avaliação de Software.

\begin{abstract}
This paper discusses the need for the study of government transparency from the perspective of information technology. So, is presented the building of an Evaluation Methodology of Municipal Transparency Websites, in light of the Standards series ISO/IEC 25000, and the Brazilian law. The proposed model contains 443 appraisal items, divided into a specific indicator to measure the level of transparency the Legislative Power, and another to the municipal Executive Power. The built methodology was based on objective criteria for the allocation of weights to each indicator and had focus on reducing the degree of subjectivity of the process of execution of the evaluation. The work also includes the development of an operational supporting software for the evaluation process, speeding up the fieldwork.
\end{abstract}

Permission to make digital or hard copies of all or part of this work for personal or classroom use is granted without fee provided that copies are not made or distributed for profit or commercial advantage and that copies bear this notice and the full citation on the first page. To copy otherwise, or republish, to post on servers or to redistribute to lists, requires prior specific permission and/or a fee.

SBSI 2016, May 17-20, 2016, Florianópolis, Santa Catarina, Brazil.

Copyright SBC 2016.
The methodology was applied in the execution the measurement of transparency of cities of the Espírito Santo State, Brazil, and the results showed a low degree of achievement of established criteria.

\section{Categories and Subject Descriptors}

H.3.4 [Information Storage And Retrieval]: Systems and Software - Performance evaluation (efficiency and effectiveness); H.5.2 [Information Interfaces And Presentation]: User Interfaces - Evaluation/methodology;

\section{General Terms}

Measurement, Design, Verification

\section{Keywords}

Transparency; Electronic Government; Software Evaluation .

\section{INTRODUÇÃO}

A Teoria da Agência foi formulada para analisar as relações entre os diversos stakeholders no contexto da Governança Corporativa de entidades Privadas [1]. No entanto, a aplicabilidade de seus conceitos alcança diversas áreas do conhecimento, inclusive a Administração Pública.

Isto porque, quando um indivíduo é escolhido dentre seus pares para atuar como governante eleito, ali fica estabelecida uma Relação de Agência [2]. Nesta relação, os desejos ou os objetivos dos diferentes participantes estão em constante conflito, surgindo, então o Problema de Agência [3], cuja principal estratégia de mitigação é a difusão de práticas visando ao incremento da Transparência [2].

Além disso, o incremento da transparência governamental tem reflexos na redução da pobreza e da fome, no enfrentamento aos problemas climáticos, na melhoria da saúde, dentre tantas outras metas e indicadores que integram os Objetivos de Desenvolvimento do Milênio, sancionados por 189 países na Cúpula do Milênio das Nações Unidas [4]. Com isso, a transparência é, também, um componente fundamental para que a humanidade consiga alcançar os objetivos de desenvolvimento almejados. Isto porque somente através dela é possível aferir o cumprimento dos compromissos que cada nação assumiu [5].

Soma-se a isso, ainda, a constatação de que o incremento da transparência governamental traz como resultado a redução dos índices de corrupção, em todos os níveis de todas as esferas de poder [6], o que demonstra a grande relevância do tema. 
Exemplos de práticas de governos transparentes vão desde a postura de disposição em fornecer respostas aos questionamentos provenientes dos cidadãos, até a adoção de políticas públicas com ações voltadas especificamente para a maior difusão das informações custodiadas pelo Estado.

No Brasil, diversas normas legais e infralegais estabelecem que a gestão transparente é uma obrigação do administrador público, e determinam o uso de ferramentas viabilizadas pela Tecnologia da Informação para a divulgação dos dados governamentais. Estas ferramentas são popularmente conhecidas como "Portais da Transparência”. [7]

Contudo, as pesquisas que visam medir a transparência dos entes federativos brasileiros são oriundas de áreas do conhecimento como Ciências Contábeis, Direito Público, Ciências Sociais e Administração Pública, tornando necessária a avaliação dos mesmos sob a ótica da Tecnologia da Informação, que é o principal objetivo do presente trabalho.

Na seção 2 são apresentados os principais conceitos relativos ao tema da Transparência e da avaliação de software, bem como a revisão bibliográfica com os trabalhos relacionados. A seção 3 descreve a metodologia de pesquisa aplicada e os passos seguidos para se alcançarem os resultados, descritos na seção 4 . Por fim, a quinta seção contém a análise dos resultados obtidos, e as expectativas dos próximos passos da pesquisa aqui apresentada, bem como sugestões de trabalhos futuros.

\section{FUNDAMENTAÇÃO TEÓRICA}

A definição do termo "Transparência" não é precisa [8] [9], entretanto, no contexto do presente trabalho, é possível entender que são transparentes as "instituições que permitem que os cidadãos vejam através de suas estruturas, e possam assim tomar consciência dos fluxos informacionais que transpassam os centros de poder" [7]. Em uma abordagem mais ampla, além de relacionar-se ao fluxo de informações, as instituições transparentes devem ser aquelas que cuidam da qualidade da informação para que seja mais bem compreendida, e se preocupam em facilitar o uso dessa informação, especialmente para favorecer a accountability ${ }^{1}[8]$.

Assim, de forma simplificada, o "conceito de transparência está associado à divulgação de informações por parte dos governos para atores internos e externos" [9], e pressupõe, então, a disponibilização de dados custodiados pelo Estado para as mãos de quaisquer interessados.

Na regulamentação da Lei de Acesso à Informação brasileira, foram cunhados os termos "Transparência Ativa" e "Transparência Passiva" [10], sendo que o primeiro se refere à publicação de informações de interesse geral, por parte do Estado, de forma proativa, independentemente de solicitação, ao passo que o segundo é a capacidade e disponibilidade de o Estado responder aos pedidos de informações específicas provenientes de qualquer solicitante.

Por exemplo, o ato de município disponibilizar em seu Portal os salários de todos os servidores públicos se refere à Transparência Ativa, enquanto que o atendimento de uma solicitação de cópia de

\footnotetext{
${ }^{1} \mathrm{O}$ termo "Accountability" não possui uma tradução direta para o português, e seu conceito inclui a responsabilização dos eleitos, através da fiscalização possibilitada pela transparência [8].
}

documento específico, protocolizada na ouvidoria de uma universidade federal, representa uma ação de Transparência Passiva.

Com isso, o presente trabalho cuida de propor uma metodologia e uma ferramenta para avaliar a Transparência Ativa dos municípios brasileiros. A proposta se diferencia dos trabalhos correlatos por estar amparada em normas de Tecnologia da Informação, buscar conferir menor grau de subjetividade no processo de análise, medir o cumprimento integral de toda legislação relacionada e incluir uma ferramenta de apoio.

\subsection{Legislação sobre Transparência}

O ponto de partida da legislação acerca do tema da Transparência é o artigo 19 da Declaração Universal dos Direitos Humanos, de 1948 [11], no qual é estabelecido que "Todo o indivíduo tem direito à liberdade de opinião e de expressão, o que implica o direito de não ser inquietado pelas suas opiniões e o de procurar, $\underline{\text { receber e difundir, sem consideração de fronteiras, informações e }}$ ideias por qualquer meio de expressão.” (grifos dos autores).

Neste trecho, é possível notar, pelos grifos, que, o direito de acesso à informação está contido no princípio da liberdade de expressão a que se trata o referido artigo [8]. Conteúdo semelhante se encontra na Convenção Americana Sobre Direitos Humanos (Pacto de San José, da Costa Rica), de 1969 [12].

Já a Constituição Federal Brasileira de 1988 [13] estabelece, em seu artigo $5^{\circ}$, inciso XXXIII, que "todos têm direito a receber dos órgãos públicos informações de seu interesse particular, ou de interesse coletivo ou geral, que serão prestadas no prazo da lei, sob pena de responsabilidade, ressalvadas aquelas cujo sigilo seja imprescindível à segurança da sociedade e do Estado".

O mesmo artigo $5^{\circ}$ ainda determina que "LX - a lei só poderá restringir a publicidade dos atos processuais quando a defesa da intimidade ou o interesse social o exigirem".

Além disso, o artigo 37 da Carta Magna também trata da transparência governamental, ao estabelecer que a Administração Pública obedecerá, dentre outros, princípio da publicidade.

Já as disposições da legislação infraconstitucional, vêm dar efetividade aos direitos vistos acima, inclusive com o estabelecimento de padrões e procedimentos para a divulgação de informações públicas.

Em primeiro lugar, a Lei de Responsabilidade Fiscal (LRF) [14], com a redação dada pela Lei Capiberibe [15], em seus artigos 48 e 48-A, exige a divulgação de informações acerca das leis orçamentárias, das receitas e das despesas públicas, na Internet, atualizadas em tempo real.

Com a inclusão destes dois artigos na LRF, surgiu a terminologia dos "Portais da Transparência", seguindo nomenclatura adotada pelo Poder Executivo Federal. Estes portais são websites que recebem dados dos sistemas de informações contábeis e as disponibilizam para amplo acesso do público. É o Portal da Transparência, assim, o instrumento pelo qual a maioria dos entes públicos busca atender as determinações acima descritas.

Importante destacar que, apesar de receberem maior atenção, os trechos da LRF em tela, não exigem apenas a divulgação das receitas e despesas, pois, no caput do artigo 48, também é exigida a divulgação, por meios eletrônicos, das leis orçamentárias, 
prestações de contas, parecer prévio e, ainda, dos relatórios de Gestão Fiscal e de Execução Orçamentária [14].

Em complemento a isto, na parte final do inciso III do parágrafo único do artigo 48, é prescrito que o Poder Executivo Federal estabeleça o padrão mínimo de qualidade do Sistema que realize a divulgação de informações, o que foi atendido com a edição do Decreto 7.185/2010 [16].

Nele, foi estabelecido o detalhamento das informações mantidas nos Portais da Transparência. O Decreto ratificou a necessidade de publicação dos dados em meio eletrônico de fácil acesso, sem exigência de senhas, listou os tipos de dados que seriam disponibilizados, a forma de atualização e a formatação dos mesmos.

Por outro lado, o termo "tempo real", constante na Lei 131/2010 [14], foi interpretado, no artigo $2^{\circ}$ do Decreto 7.185/2010 [16], como a disponibilização das informações "até o primeiro dia útil subsequente à data do registro contábil".

Em seu artigo $7^{\circ}$, o Decreto [16] detalha quais as informações que devem ser disponibilizados no Portal, por exemplo, "a classificação orçamentária, especificando a unidade orçamentária, função, subfunção,(...)”.

No entanto, em se tratando de divulgação de informações relativas às finanças públicas, para apurar precisamente o conteúdo que deve conter cada seção do website governamental de transparência, é necessário combinar as normas sobre transparência, que estabelecem quais informações devem ser disponibilizadas, com as normas sobre contabilidade pública, que estabelecem o conteúdo e o formato destas informações.

Com isso, fazem parte do arcabouço legal que embasou o presente trabalho, a Lei 4.320/1964 [17], notadamente seus artigos 11, 61, 63, 64 e 88, bem como a Portaria Conjunta STN/SOF no 1/2014 [18], que aprova a Parte I do Manual de Contabilidade Aplicada ao Setor Público (MCASP) e, ainda, a Portaria Interministerial STN/SOF $n^{\circ} 163 / 2001$ [19], que versa, em seu artigo $3^{\circ}$, sobre a classificação da despesa pública.

Destaca-se que as normas acima não dispõem sobre transparência, mas são fundamentais para definir a estrutura das informações contábeis que devem ser disponibilizadas nos Portais da Transparência.

Já a Lei no 12.527/2011 [20], comumente conhecida como Lei de Acesso à Informação (LAI), amplia ainda mais o rol de informações que devem ser divulgadas pelo Estado, bem como as formas de divulgação das mesmas.

O seu artigo $3^{\circ}$ institui as diretrizes de transparência que a Administração Pública deve seguir, como "I - observância da publicidade como preceito geral e do sigilo como exceção" e "III utilização de meios de comunicação viabilizados pela tecnologia da informação".

A partir daí já é possível estabelecer uma série de informações cuja divulgação deve ser realizada pela Internet, para além do rol da Lei 131/2009 [15]. No entanto, os artigos $7^{\circ}$ e $8^{\circ}$ da LAI [20] cuidaram de detalhar com maior precisão aquilo que se espera de uma atuação de Transparência Ativa, indicando as informações mínimas que devem ser disponibilizadas, bem como requisitos técnicos das ferramentas de divulgação.
Merece destaque o parágrafo terceiro do artigo $8^{\circ}$, que determina que "Os sítios (...) deverão, na forma de regulamento, atender, entre outros, aos seguintes requisitos: I - conter ferramenta de pesquisa de conteúdo que permita o acesso à informação de forma objetiva, transparente, clara e em linguagem de fácil compreensão; II - possibilitar a gravação de relatórios em diversos formatos eletrônicos, inclusive abertos e não proprietários, tais como planilhas e texto, de modo a facilitar a análise das informações; III - possibilitar o acesso automatizado por sistemas externos em formatos abertos, estruturados e legíveis por máquina; (...); V garantir a autenticidade e a integridade das informações disponíveis para acesso (...)".

Isso mostra que o legislador brasileiro cuidou de incluir temas relativos aos detalhes tecnológicos dos requisitos dos Portais da Transparência em uma legislação de tema mais abrangente, demonstrando que a correta avaliação do cumprimento das leis sobre Transparência é dependente de uma metodologia de avaliação considerando os aspectos de Tecnologia da Informação.

\subsection{Normas Sobre Avaliação De Software}

Muitas das ações necessárias para ampliação da transparência de um ente governamental são apoiadas na Tecnologia da Informação, uma vez que a Internet é o meio mais adequado para a difusão das informações públicas, e estas se encontram, na maioria das vezes, armazenadas em sistemas de bancos de dados.

Uma vez que o Portal de Transparência seja uma ferramenta de software, a metodologia de avaliação utilizada no presente trabalho foi concebida tendo por referência, além da legislação, os critérios estabelecidos para avaliações de qualidade de produtos de software.

Estes critérios estão estabelecidos a partir do conjunto de normas SQuaRE (Software product Quality Requirementes and Evaluation), estabelecidas com a edição da ISO/IEC 25000 [21], que trata da caracterização e medição de qualidade de produtos de software. Ela tem como objetivo melhorar e unificar os processos pertinentes à qualidade de software, sendo eles a especificação de requisitos, a medição e avaliação de qualidade. As normas SQuaRE são a reformulação das normas ISO/IEC 9126 e ISO/IEC 14598 [22] e possuem cinco divisões: requisitos de qualidade, modelo de qualidade, gerenciamento de qualidade, medições e avaliação.

Neste conjunto, a ISO/IEC 25040 [23] define uma visão geral do Processo de Avaliação de qualidade, dividindo-o em cinco etapas principais, conforme figura a seguir:

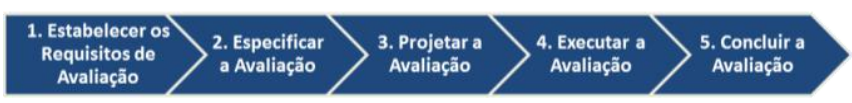

Figura 1. Etapas do Processo de Avaliação

Com isso, a avaliação de um Portal da Transparência deve ser realizada seguindo as etapas prescritas no processo acima, com as devidas adaptações à realidade de cada organização avaliadora.

Já a construção do modelo de qualidade do produto de software, a ser utilizado para a avaliação dos Portais de Transparência dos municípios, foi realizada a partir das definições da Norma ISO/IEC 25010 [24]. Ela estabelece que a qualidade do produto é categorizada em características e subcaracterísticas, sendo estas ainda divididas em atributos. 
Assim, a mesma norma define oito características de Qualidade do Produto que os softwares devem apresentar: Adequação da Funcionalidade, Eficiência do Desempenho, Compatibilidade, Usabilidade, Confiabilidade, Segurança, Manutenibilidade e Portabilidade.

Também são estabelecidas na ISO 25010 as cinco características de Qualidade em Uso, que caracterizam o impacto que o software exerce sobre o usuário, conforme abaixo ilustrado:

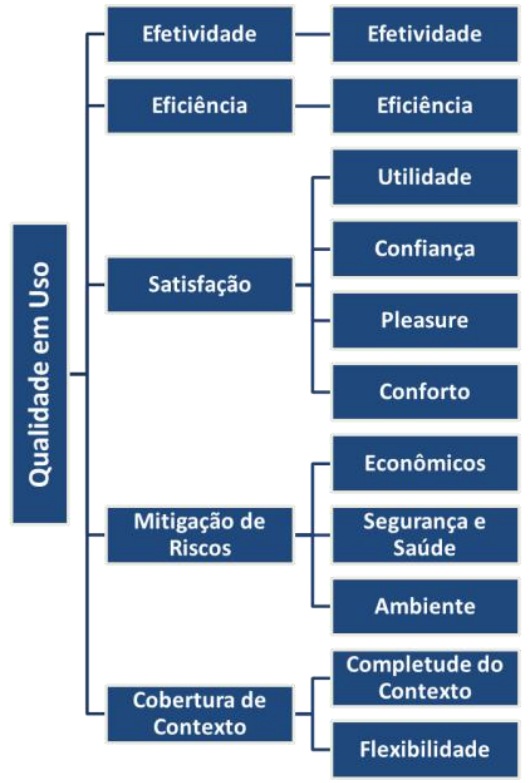

Figura 2. Características da Qualidade em Uso

Cada uma das características e subcaracterísticas são descritas e detalhadas na referida norma, demonstrando sua conceituação e aplicação.

Nota-se, todavia, que, dependendo das condições, nem sempre será possível avaliar todas as características e subcaracterísticas de qualidade em um Portal da Transparência, haja vista que a medida de algumas delas exige acesso ao código-fonte ou à infraestrutura de hospedagem da aplicação.

\subsection{Trabalhos Correlatos}

A primeira avaliação de Portais da Transparência brasileiros que obteve grande repercussão foi o trabalho da Associação Contas Abertas, em 2010 [25], que é reeditado a cada dois anos.

Nesse trabalho, é descrita uma metodologia que visa avaliar se os portais dos Estados Brasileiros apresentam o conteúdo exigido pela Lei, e se atendem as boas práticas de usabilidade que especialistas da Organização elegeram.

Contudo o aspecto do Portal da Transparência como um software é pouco abordado, e a valoração de cada quesito avaliado apresenta um grau elevado de subjetividade, diferentemente do que ocorre no presente trabalho.

Os resultados da pesquisa servem de insumo para diversos outros trabalhos, como [31], [32], [33] e [34], que os consideram como indicadores para outras análises e correlações, ou reaplicam a metodologia em diferentes contextos.

As mesmas considerações são válidas no trabalho [26], que apresenta uma metodologia de avaliação baseada apenas nos aspectos legais e nas boas práticas postuladas pelo Fundo Monetário Internacional, também contendo alto grau de subjetividade nas análises.

Já a pesquisa descrita em [27], que avaliou a transparência ativa dos municípios de Minas Gerais, também mede alguns aspectos de software, como acessibilidade, disponibilidade e confiabilidade, mas não é apresentado o método nem os indicadores utilizados para avaliar estes aspectos.

Uma metodologia mais ampla e objetiva foi proposta por [28], porém, abordava aspectos relacionados ao atendimento de pedidos por parte do órgão público, qualidade da legislação, entre outros aspectos que fogem do escopo da avaliação de uma ferramenta tecnológica.

A Controladoria Geral da União (CGU), por sua vez, publicou em 2015, a segunda edição da Escala Brasil Transparente [29], na qual foi avaliada a transparência de 1.613 entes federativos.

No entanto, foi estudado apenas o atendimento da Transparência Passiva, em uma pesquisa com somente 12 (doze) itens de avaliação, todos relacionados exclusivamente ao atendimento de artigos da Lei 12.527/2011, ao passo que o presente trabalho cuida de avaliar a Transparência Ativa, a partir de centenas de itens de avaliação.

$\mathrm{Na}$ mesma época, o Ministério Público Federal divulgou o Ranking da Transparência [30], que avaliou todos os 5.568 municípios brasileiros e, dado o tamanho da amostra, utilizou uma metodologia também reduzida, com apenas 16 (dezesseis) quesitos de avaliação, checando o cumprimento de alguns itens legais.

Isso mostra que o estudo dos Portais da Transparência considerando os softwares que eles são, isto é, a avaliação destes Portais sob a ótica da Tecnologia da Informação, representa um campo de pesquisa ainda pouco explorado, do qual cuida o presente trabalho.

\section{METODOLOGIA}

Inicialmente, conforme o modelo da ISO/IEC 25040 [23], foi definida uma estrutura hierárquica de classificação das informações a serem avaliadas, sob a qual foi construída a metodologia de avaliação.

Em seguida, foi feita a revisão da legislação brasileira sobre Transparência, identificando os itens cuja avaliação é necessária para aferir a característica "Adequação da Funcionalidade" expressa na ISO/IEC 25010 [24].

Nesta etapa, foram elencados 443 (quatrocentos e quarenta e três) quesitos a serem verificados a cada município avaliado. Essa grande quantidade de itens de avaliação fez com que a presente pesquisa se dividisse em outras duas etapas, com a antecipação do trabalho de campo, para avaliar apenas o cumprimento da legislação e, em seguida, após validação dos resultados, serem acrescentados à metodologia as demais características de qualidade propostos pela norma técnica.

Assim, para ser realizada uma medição quantitativa da transparência, isto é, atribuir um indicador, um número que pudesse expressar o grau de transparência de cada entidade avaliada, foi estabelecido que a pontuação máxima possível de ser alcançada fosse o total de 1.000 (mil) pontos, a serem distribuídos a cada item de avaliação. 
Esta distribuição foi realizada com a aplicação de um método topdown, isto é, foram atribuídas pontuações nos níveis de agrupamento mais elevados e, em seguida, redistribuídos os resultados nos níveis mais baixos, até alcançarem o piso da hierarquia categorizada.

Esta distribuição contou com o apoio de um especialista do domínio, que considerou critérios de relevância legal (o grau de exigência legal quanto à divulgação de cada item), relevância social ( o quanto a divulgação do item é de interesse da sociedade em geral), materialidade (o valor financeiro envolvido na divulgação do item) e risco ( a medida que a divulgação de cada item favorece a redução da corrupção).

Para cada critério, foram atribuídos pesos que variam de 0 a 3 e, então, utilizada a soma dos pesos de cada critério como fator de ponderação para distribuição da pontuação. Após os cálculos, foram feitos ajustes de aproximação, com o fim de facilitar a análise dos resultados. A tabela a seguir ilustra a distribuição dos pesos entre os diferentes Tipos de Informação na construção do indicador de transparência do Poder Executivo.

Tabela 1. Critério de distribuição da pontuação

\begin{tabular}{|l|c|c|c|c|c|c|c|c|}
\hline \multirow{2}{*}{ TIPO DE INFORMAÇÃo } & $\begin{array}{c}\text { RELEV. } \\
\text { LEGAL }\end{array}$ & $\begin{array}{c}\text { RELEV. } \\
\text { SOCIAL }\end{array}$ & $\begin{array}{c}\text { MATERIA- } \\
\text { LIDADE }\end{array}$ & RISCO & TAMANHO & TOTAL & $\%$ & AJUSTE \\
\hline Aspectos Gerais & 2 & 3 & 1 & 2 & 1 & 9 & $11 \%$ & 100 \\
\hline Despesas & 3 & 3 & 3 & 3 & 3 & 15 & $18 \%$ & $\mathbf{2 0 0}$ \\
\hline Receitas & 3 & 2 & 3 & 3 & 1 & 12 & $14 \%$ & $\mathbf{1 5 0}$ \\
\hline Pessoal & 1 & 3 & 2 & 3 & 2 & 11 & $13 \%$ & $\mathbf{1 5 0}$ \\
\hline Licitações e Contratos & 2 & 2 & 2 & 3 & 2 & 11 & $13 \%$ & 100 \\
\hline Gestão Fiscal & 3 & 1 & 3 & 2 & 1 & 10 & $12 \%$ & 100 \\
\hline Transferências & 1 & 2 & 1 & 2 & 1 & 7 & $8 \%$ & 100 \\
\hline Patrimônio & 1 & 2 & 2 & 3 & 1 & 9 & $11 \%$ & $\mathbf{1 0 0}$ \\
\hline
\end{tabular}

Em seguida, visando reduzir o grau de subjetividade do processo de execução da avaliação, foi necessário, também, prever as diferentes situações que cada item de avaliação pode ser encontrado e, então, definir o percentual de atingimento da pontuação total do item representados pela situação encontrada.

Por exemplo, na avaliação da divulgação do CNPJ das empresas que recebem pagamentos do município, o pesquisador pode verificar que a informação não existe, se parte dela é oculta, ou se somente é divulgado em granularidade elevada. Assim, cada situação desta representa um diferente percentual de atingimento da nota total do item.

$\mathrm{Na}$ construção da Metodologia de Avaliação, também, foram definidos atributos qualitativos a cada item, como a descrição explicativa da exigência do item, o critério legal ou normativo que embasou sua inclusão na metodologia, o identificador do grau de exigência da legislação e as diferentes situações que podem ser encontradas.

Feito isso, foi realizada a validação da primeira etapa da metodologia, com uma verificação do grau de transparência de todos os 78 (setenta e oito) municípios do Estado do Espírito Santo. O processo de execução da avaliação consistiu em localizar cada item no Portal da Transparência do ente avaliado, e selecionar, dentre as possíveis situações esperadas, qual foi a situação encontrada.

No entanto, para suportar o grande volume de informações tratado, foi necessário o desenvolvimento de um Software para apoiar o processo de avaliação. Assim, surge o SAPo (Sistema de Avaliação de Portais), que foi desenvolvido exclusivamente para atender as demandas do presente trabalho.
O software possui como requisitos suportar a modelagem dos indicadores de transparência, organizar e gerar os objetos de avaliação, com base nos indicadores, bem como fornecer meios para agilizar e armazenar os resultados do processo de avaliação.

É um software multiusuário, em plataforma WEB, desenvolvido integralmente com ferramentas livres, sendo utilizado, para o back-end, o Fat-Free Framework, que suporta a linguagem PHP [35], ao passo que o front-end foi construído usando Angular JS [36]. Para o banco de dados foi escolhido o MySQL. Na figura a seguir, é apresentada uma tela do SAPo.

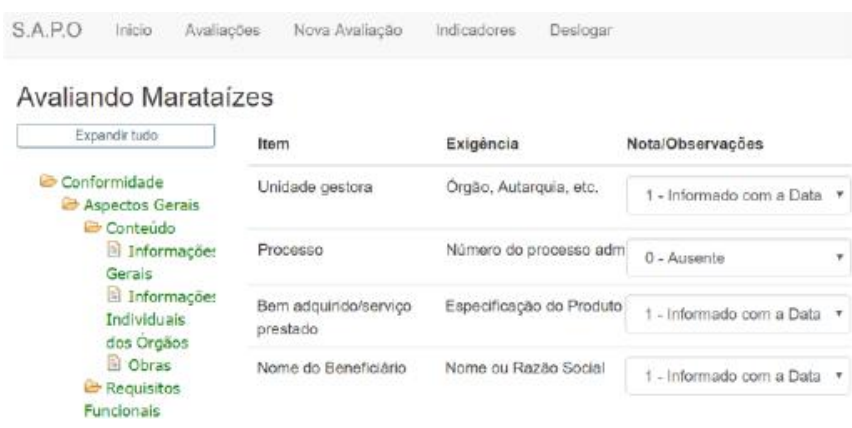

Figura 3. Tela do Sistema de Avaliação de Portais

Todos os dados coletados com o uso do SAPo foram, então, analisados a partir da execução de consultas ao banco de dados do Software, gerando, assim, os achados a seguir descritos.

\section{RESULTADOS 4.1 O Índice De Transparência Municipal: ITM-e}

Tendo em vista as diferenças orçamentárias e funcionais existentes entre os poderes executivo e legislativo, foram construídos dois indicadores de transparência municipal: o ITM-e Executivo e o ITM-e Legislativo, cada um sendo aplicado para a avaliação dos respectivos poderes.

A estrutura hierárquica de classificação das informações avaliadas tem seu conteúdo conforme figura a seguir:

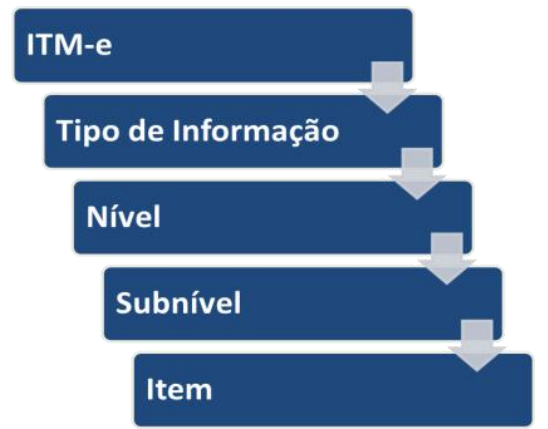

Figura 4. Níveis do ITM-e

O Tipo de Informação é a categoria que agrupa de forma mais ampla as informações que devem ser disponibilizadas pelos poderes municipais. Tem por função organizar o processo de avaliação, bem como possibilitar a análise setorizada dos resultados. A definição de cada tipo se deu pela relevância material e legal de seu conteúdo. Desta forma, chegou-se aos seguintes tipos para o Poder Executivo: Aspectos Gerais, 
Despesas, Receitas, Pessoal, Licitações e Contratos, Gestão Fiscal, Patrimônio e Transferências.

Já para o Poder Legislativo, os tipos são Aspectos Gerais, Despesas, Pessoal, Licitações e Contratos, Gestão Fiscal, Patrimônio e Produção Legislativa.

Cada Tipo de Informação pode, então, ser dividido em até dois Níveis, que são "Conteúdo" e "Requisitos Funcionais". Esta subdivisão se fez necessária para segregar os itens que se referem às informações que se buscam no Portal da Transparência, das exigências relativas à forma com que estas informações devem ser disponibilizadas.

Os "Requisitos Funcionais" podem se subdividir em até outros três Subníveis: "Apresentação dos Dados", "Busca dos Dados", e "Variação dos Dados no Tempo", conforme as exigências aplicáveis a cada item avaliado.

Já no nível "Conteúdo", são distribuídos outros 32 (trinta e dois) Subníveis, sob os quais, mais uma vez, são agrupadas informações semelhantes, conforme o exemplo:

Tabela 2. Exemplo de Tipo, Níveis e Subníveis

\begin{tabular}{l} 
Licitações e Contratos \\
Conteúdo \\
Bens e Produtos Adquiridos \\
Contratos Administrativos \\
Licitações Concluídas \\
Licitações em Andamento \\
Requisitos Funcionais \\
Apresentação dos Dados \\
Busca dos Dados \\
\hline Variação dos Dados no Tempo
\end{tabular}

Por fim, em cada Subnível foram detalhados os Itens de avaliação, que expressam, por sua vez, as propriedades da ferramenta, dos dados, ou do conteúdo que se pretende avaliar em cada Portal. O item representa o nível mais granular de especificação da informação buscada em cada objeto de avaliação.

$\mathrm{Na}$ metodologia elaborada, foram identificados 233 (duzentos e trinta e três) itens de avaliação no Poder Executivo, e outros 210 (duzentos e dez) itens de avaliação no Poder Legislativo. A seguir é apresentado um exemplo de item:

Tabela 3. Exemplo de Item de Avaliação

\begin{tabular}{|l|l|}
\hline Item & Íntegra do Edital de Licitação \\
\hline Critério & $\begin{array}{l}\text { Lei } 12.527 / 2011, \operatorname{art.~} 8^{\circ}, \S 1^{\mathbf{o}} \text { e art. } 7^{\circ}, \text { VI } \\
\text { Lei } 8.666 / 1994, \text { art. } 3^{\circ}, \S 3^{\circ} \text { e art. } 21, \S 1^{\circ} \\
\text { Lei } 10.520 / 2002, \text { ar. } 4^{\circ}\end{array}$ \\
\hline Exigência & $\begin{array}{l}\text { Disponibilizar o edital e seus anexos para } \\
\text { download de qualquer interessado }\end{array}$ \\
\hline Nota Máxima & 1 \\
\hline Critério de Pontuação & $\begin{array}{l}\text { Disponibiliza o edital, sem cadastro: } 1 \\
\text { Disponibiliza, com cadastro no site: } 0,75 \\
\text { Disponibiliza, mediante cadastro que } \\
\text { necessita de atuação do órgão: 0,5 } \\
\text { Não disponibiliza: 0 }\end{array}$ \\
\hline
\end{tabular}

Uma vez definida a metodologia de avaliação, o trabalho de campo consistiu em, efetivamente, medir o grau de transparência dos municípios capixabas, a partir do acesso aos Portais da Transparência de cada Poder de cada município, chegando aos resultados a seguir apresentados.

\subsection{Panorama Da Transparência Municipal}

De modo mais amplo, verificou-se que, em termos gerais, a transparência pública municipal do Estado do Espírito Santo apresenta os seguintes indicadores de atendimento:

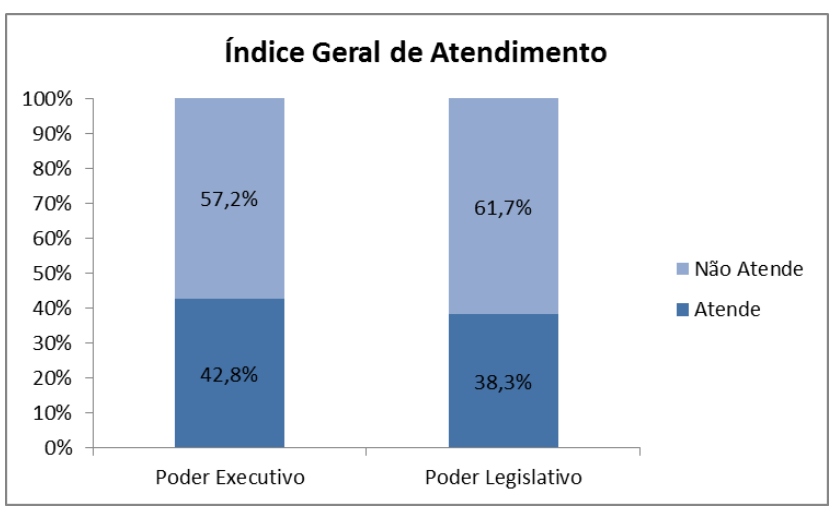

Figura 5. Panorama da Transparência no ES

Isso mostra que, de forma geral, $42,8 \%$ do que a metodologia considera de desejável atendimento é atingido pelos poderes executivos municipais e 38,3\% dos itens esperados são atendidos pelos entes do poder legislativo municipal.

No entanto, o ITM-e faz distinção entre itens que se referem a conteúdo, isto é a informação propriamente dita, e itens que se referem ao formato dos dados, como frequência de atualização. Assim, o indicador acima pode ser dividido da seguinte maneira:

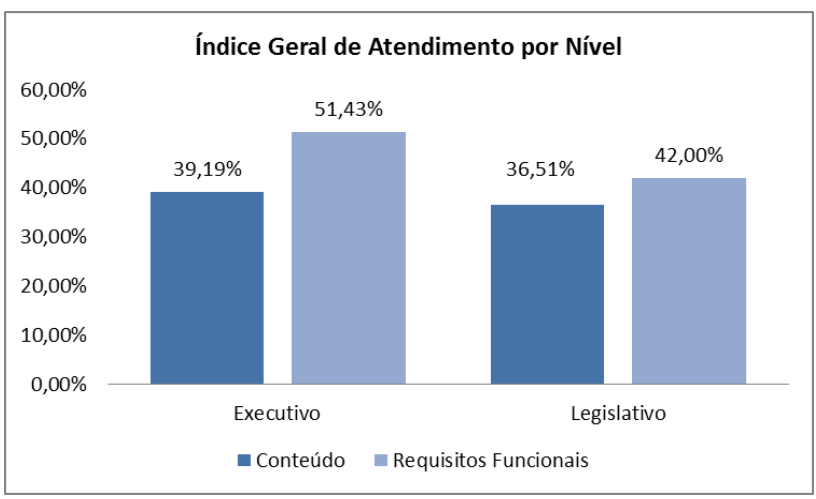

Figura 6. Resultados Gerais por Nível

Assim, nota-se que os quesitos relativos ao conteúdo são menos atendidos do que os quesitos relativos ao formato dos dados, apesar de ambos apresentarem indicadores baixos. Já, distribuindo os resultados por tipo de informação, verifica-se o que segue:

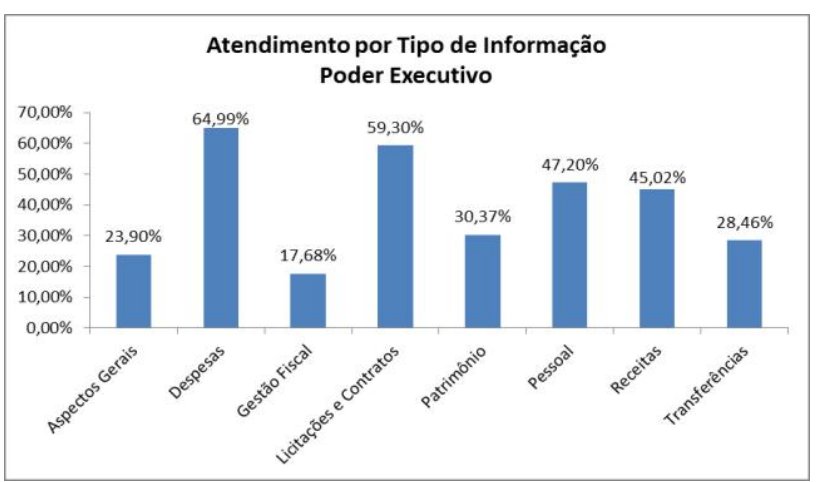

Figura 7. Distribuição dos Resultados por Tipo de Informação - Poder Executivo 


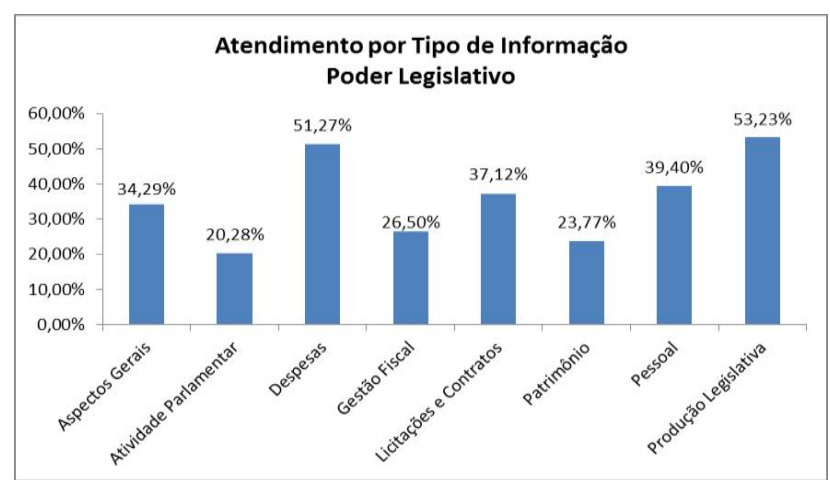

Figura 8. Distribuição dos Resultados por Tipo de Informação - Poder Legislativo

Destaca-se que os percentuais de atendimento dos gráficos acima estão consolidados considerando o conteúdo e o formato dos dados. Importante esclarecer que os percentuais apresentados se referem à média da pontuação obtida por cada município, e não ao percentual quantitativo de municípios que atenderam aos critérios.

\section{3 Índice De Transparência Por Município}

O somatório da nota de cada item em cada município possibilita realizar a medida da transparência por ente, na qual foi identificado o seguinte:

\begin{tabular}{|c|l|l|l|l|l|}
\hline & Poder Executivo & Nota & & Poder Legislativo & Nota \\
\hline $1^{\circ}$ & Castelo & $63,48 \%$ & $1^{\circ}$ & Domingos Martins & $73,60 \%$ \\
\hline $2^{\circ}$ & Venda Nova do Imigrante & $61,65 \%$ & $2^{\circ}$ & Venda Nova do Imigrante & $71,20 \%$ \\
\hline $3^{\circ}$ & Linhares & $59,23 \%$ & $3^{\circ}$ & Anchieta & $65,83 \%$ \\
\hline $4^{\circ}$ & Santa Maria de Jetibá & $57,93 \%$ & $4^{\circ}$ & Pinheiros & $63,88 \%$ \\
\hline $5^{\circ}$ & Vitória & $57,65 \%$ & $5^{\circ}$ & Laranja da Terra & $62,73 \%$ \\
\hline $6^{\circ}$ & Conceição do Castelo & $56,03 \%$ & $6^{\circ}$ & Ibiraçu & $61,70 \%$ \\
\hline $7^{\circ}$ & Fundão & $55,50 \%$ & $7^{\circ}$ & Cachoeiro de Itapemirim & $58,70 \%$ \\
\hline $8^{\circ}$ & Governador Lindenberg & $54,70 \%$ & $8^{\circ}$ & Guarapari & $58,23 \%$ \\
\hline $9^{\circ}$ & Mantenópolis & $54,18 \%$ & $9^{\circ}$ & Vila Valério & $56,63 \%$ \\
\hline $10^{\circ}$ & Jerônimo Monteiro & $54,18 \%$ & $1^{\circ}$ & Fundão & $56,48 \%$ \\
\hline
\end{tabular}

Figura 9. Ranking dos Municípios com Maior Transparência Já na outra ponta, verifica-se o seguinte:

\begin{tabular}{|l|l|l|l|l|l|}
\hline & Poder Executivo & Nota & & Poder Legislativo & Nota \\
\hline $69^{\circ}$ & São Roque do Canaã & $30,95 \%$ & $69^{\circ}$ & Guaçuí & $17,10 \%$ \\
\hline $70^{\circ}$ & Mimoso do Sul & $26,75 \%$ & $70^{\circ}$ & Ibitirama & $10,90 \%$ \\
\hline $71^{\circ}$ & São José do Calçado & $26,68 \%$ & $71^{\circ}$ & Mimoso do Sul & $10,25 \%$ \\
\hline $72^{\circ}$ & Guaçuí & $25,75 \%$ & $72^{\circ}$ & Bom Jesus do Norte & $0,80 \%$ \\
\hline $73^{\circ}$ & Anchieta & $25,28 \%$ & $73^{\circ}$ & Divino de São Lourenço & $0,20 \%$ \\
\hline $74^{\circ}$ & Baixo Guandu & $24,83 \%$ & $74^{\circ}$ & São Domingos do Norte & $0,00 \%$ \\
\hline $75^{\circ}$ & Guarapari & $22,30 \%$ & $75^{\circ}$ & Mucurici & $0,00 \%$ \\
\hline $76^{\circ}$ & Divino de São Lourenço & $10,08 \%$ & $76^{\circ}$ & Montanha & $0,00 \%$ \\
\hline $77^{\circ}$ & Ecoporanga & $2,40 \%$ & $77^{\circ}$ & Ponto Belo & $0,00 \%$ \\
\hline $78^{\circ}$ & Pinheiros & $2,00 \%$ & $78^{\circ}$ & São Roque do Canaã & $0,00 \%$ \\
\hline
\end{tabular}

Figura 10. Ranking dos Municípios com Menor Transparência

Os entes com nota zero são aqueles que não disponibilizam sequer um website institucional.

Os resultados mostram que, apesar de o índice de atendimento geral do Poder Executivo superar o Poder Legislativo, os melhores indicadores se encontram no poder legislativo. Contudo, ao mesmo tempo, os piores indicadores também se encontram no
Legislativo, levando a situação geral do poder a um patamar inferior.

\section{CONSIDERAÇÕES FINAIS}

A metodologia de avaliação desenvolvida se mostrou robusta, abarcando uma grande quantidade de itens de avaliação, e a estratégia de pré-definir as possíveis situações encontradas tornou o processo de avaliação ágil e objetivo, uma vez que consistiu basicamente em informar ao software qual a situação verificada in loco.

Além disso, os resultados mostram a necessidade de ações por parte dos gestores municipais visando ao incremento do grau de transparência de cada ente avaliado. Às instituições de controle externo, fica evidenciada, ainda, a necessidade de atuação mais incisiva neste tema da transparência, até porque a Lei prevê sanções por descumprimento de diversos itens aqui avaliados.

$\mathrm{Na}$ continuação desta pesquisa, será feita a ampliação da metodologia com a inclusão de itens de avaliação visando medir uma maior quantidade de atributos especificados na Norma, como usabilidade, acessibilidade, aprensibilidade e integridade. Também serão realizadas novas análises nos resultados, visando auxiliar no entendimento dos motivos que levam aos diferentes graus de transparência.

Assim, este trabalho seguirá com análises estatísticas mais robustas dos resultados, e cruzamentos como ITM-e versus PIB (Produto Interno Bruto) ou ITM-e versus População. Também serão verificados o índice de atendimento por norma legal e por item.

Para trabalhos futuros, são sugeridos estudos comparativos dos resultados aplicados com o ITM-e e outras metodologias aos mesmos entes, bem como a ampliação da quantidade de itens que compõe o ITM-e e, ainda, a evolução da ferramenta de apoio ao processo de avaliação.

\section{REFERENCIAS}

[1] Fontes Filho, J. R. Governança organizacional aplicada ao setor público. VIII Congreso Internacional del CLAD sobre la Reforma del Estado y de la Administración Pública. (Panamá, Out. 2003)

[2] de Arruda, G. S.; Madruga, S. R.; de Freitas Junior, N. I. 2008. A governança corporativa e a teoria da agência em consonância com a controladoria. Revista de Administração da UFSM.

[3] Jensen M. abd Meckling, W. 1976. Theory of the firm: Managerial behavior, agency cost, and ownership structure. In Journal of Financial Economics. p. 305-360

[4] United Nations Information Centre. 2000. United Nations Millennium Declaration. Nova York.

[5] International Budget Partnership. 2015; Open Budget Survey. Available in http://internationalbudget.org/wpcontent/uploads/OBS2015-Report-English.pdf

[6] Kim, S.; Kim, H. J.; Lee, H. 2009. An institutional analysis of an e-government system for anti-corruption: The case of OPEN. Government Information Quarterly, v. 26, n. 1, p. 42-50.

[7] da Silva, D. B. Transparência na Esfera Pública Interconectada. Dissertação de Mestrado em Processos 
Midiáticos: Tecnologia e Mercado. Faculdade Cásper Líbero, São Paulo. 2010.

[8] Angélico, F. Lei de Acesso à Informação Pública e seus possíveis desdobramentos para a accountability democrática no Brasil. Dissertação de Mestrado. Escola de Administração de Empresas de São Paulo. 2012

[9] Ribeiro, C. P. R. and Zuccolotto, R. Identificação dos Fatores Determinantes da Transparência na Gestão Pública dos Municípios Brasileiros. Concurso nacional de Monografias de Conselheiro Henrique Santilho. Tribunal de Contas do Estado de Goiás. Brasília. 2012.

[10] Brasil. Presidência da República. Decreto No 7.724, de 16 de maio de 2012

[11] Assembly, U. G. (1948). Universal declaration of human rights. UN General Assembly. Available in http://www.un.org/en/universal-declaration-humanrights/index.html

[12] OEA. Convenção Americana de Direitos Humanos. Entrada em vigor em 22 de novembro de 1968. San José. 1969.

[13] Brasil. Constituição (1988). Constituição da República Federativa do Brasil.

[14] Brasil. Lei Complementar $n^{\circ} 101$, de 4 de maio de 2000

[15] Brasil. Lei Complementar no 131, de 27 de maio de 2009

[16] Brasil. Presidência da República. Decreto n 7.185, de 27 de maio de 2010

[17] Brasil. Lei no 4.320 de 17 de março de 1964

[18] Brasil. STN/SOF - Secretaria do Tesouro Nacional and Secretaria do Orçamento Federal. Portaria Conjunta $n^{\circ} 1$, de 10 de dezembro de 2014.

[19] Brasil. STN/SOF - Secretaria do Tesouro Nacional and Secretaria do Orçamento Federal Portaria Interministerial STN/SOF n ${ }^{\circ}$ 163/2001. D.O.U. n ${ }^{\circ}$ 87-E, de 07.05.2001, Seção 1, páginas 15 a 20

[20] Brasil. Lei no 12.527, 18 de novembro de 2011

[21] ISO/IEC 25000 Software Engineering - Software product Quality Requirementes and Evaluation (SQuaRE) - Guide to SQuaRE. ISO/IEC - International Organization for Standardization and International Electrotechnical Commission, Switzerland, 1 edition, 2005

[22] Palato, H. Informática na educação -“software educacional”. Universidade Presbiteriana Makenzie. São Paulo. 2013

[23] ISO/IEC 25040 Systems and software engineering - Systems and software Quality Requirements and Evaluation
(SQuaRE) - Evaluation process. 2011, International Organization for Standardization: Switzerland

[24] ISO/IEC 25010, Systems and software engineering - Systems and software Quality Requirements and Evaluation (SQuaRE) - System and software quality models. 2011, International Organization for Standardization: Switzerland

[25] Contas Abertas. Índice de Transparência. 2010. Available in http://www.indicedetransparencia.org.br

[26] Beghin, N. and Zigoni, C. Avaliando os websites de transparência orçamentária nacionais e subnacionais e medindo impactos de dados abertos sobre direitos humanos no Brasil. Instituto de Estudos Socioeconômicos. Brasília, 2014

[27] PAIVA, C. P. R.; ZUCCOLOTTO, R. Índice de transparência fiscal das contas públicas dos municípios obtidos em meios eletrônicos de acesso público. In: XXXIII Encontro da ANPAD, São Paulo, 2009

[28] Instituto Ethos, Amarribo Brasil e Outros. Projeto Cidade Transparente. Available in http://www.cidadetransparente.com

[29] Controladoria Geral da União. "CGU divulga resultado da segunda edição da Escala Brasil Transparente". Available in http://www.cgu.gov.br/noticias/2015/11/cgu-divulgaresultado-da-segunda-edicao-da-escala-brasil-transparente

[30] Ministério Público Federal. 2015. Mapa da Transparência. Available in http://www.rankingdatransparencia.mpf.mp.br.

[31] Ranking de Competitividade dos Estados. 2015. Available in http://www.rankingdecompetitividade.org.br.

[32] Abreu, W. M., Gomes, R. C., \& Alfinito, S. (2015). Transparência Fiscal Explica Desenvolvimento Social nos Estados Brasileiros?. Sociedade, Contabilidade e Gestão.

[33] Hosser, C., Cruz, A. P. C. D., Machado, D. G., an Quintana, A. C. (2015). Portal da transparência: um estudo comparativo entre os municípios de Porto Alegre e Pelotas.

[34] Pisa, B. J. Uma proposta para o desenvolvimento do índice de avaliação da governança pública (IGovP): instrumento de planejamento e desenvolvimento do estado. 2014. $222 \mathrm{f}$. Dissertação - Universidade Tecnológica Federal do Paraná, Curitiba, 2014.

[35] Fat-Free Framework. 2016. Available in http://fatfreeframework.com/.

[36] Green, B. and Seshadri, S. (2013). AngularJS. O'Reilly Media, Inc.. 